\title{
Report from the "What is Open?" Workgroup
}

\author{
Rick, Anderson, Seth Denbo, Diane Graves, Susan Haigh, Steven Hill, Martin Kalfatovic, Roy Kaufman, \\ Catherine Murray-Rust, Kathleen Shearer, Dick Wilder, Alicia Wise
}

\begin{abstract}
The scholarly community's current definition of "open" captures only some of the attributes of openness that exist across different publishing models and content types. Open is not an end in itself, but a means for achieving the most effective dissemination of scholarship and research. We suggest that the different attributes of open exist along a broad spectrum and propose an alternative way of describing and evaluating openness based on four attributes: discoverable, accessible, reusable, and transparent. These four attributes of openness, taken together, form the draft "DART Framework for Open Access." This framework can be applied to both research artifacts as well as research processes. We welcome input from the broader scholarly community about this framework.
\end{abstract}

\section{OSI2016 workgroup question}

There is a broad difference of opinion among the many stakeholders in scholarly publishing about how to precisely define open access publishing. Are "open access" and "open data" what we mean by open? Does "open" mean anything else? Does it mean "to make available," or "to make freely available in a particular format?" Is a clearer definition needed (or maybe just better education on the current definition)? Why or why not? At present, some stakeholders see public access as being an acceptable stopping point in the move toward open access. Others see "open" as requiring free and immediate access with articles being available in CCBY format. The range of opinions between these extremes is vast. How should these differences be decided? Who should decide? Is it possible to make binding recommendations (and how)? Is consensus necessary? What are the consequences of the lack of consensus?

\section{Initial conclusions}

Our workgroup began by considering whether we should focus narrowly on open access as it relates to scholarly publishing, or whether we should take an expansive look at open scholarship writ large across all disciplines, research products and processes. In the end, we chose to view open scholarship in the broadest possible context.
A range of outputs can be made open: articles, journals, ${ }^{1}$ monographs, new forms of research, educational resources, data, materials, software code, and where appropriate, hardware. Our group noted that for journal literature, from the perspective of the user, it is the relative openness of an article that is of prime importance. It was also agreed that various versions of the journal article are effectively distinct outputs when we consider

(C) 2016 OSI2016 What Is Open? workgroup. This open access article is distributed under the Creative Commons Attribution 4.0 International License. This document reflects the combined input of the authors listed here (in alphabetical order by last name) as well as contributions from other OSI2016 delegates. The findings and recommendations expressed herein do not necessarily reflect the opinions of the individual authors listed here, nor their agencies, trustees, officers, or staff. 
openness-for example, the submitted version, accepted version, and final published version can all have different degrees of openness.

Research processes and practices can also be open. Among these processes are research methodologies, peer review, disclosure of funding sources, disclosure of negative results, other research in progress, and so on.

Our workgroup agreed that open is a means to an end, rather than an end in itself, and identified three overarching goals shared by all stakeholders that can be utilized for openness:

- Better research

- More impactful research

- Maximizing value for money.

We noted that open could benefit research in a number of ways aligned to these goals, including, but not limited to:

- More value for research expenditures: Openness does not necessarily drive down costs, but it may increase the value delivered by the investment in research.

- Faster visibility: Users have faster access to research products that are open, which may boost discovery.

- Reproducibility: For openness to serve reproducibility (an important aspect of ensuring verifiable results), the findings, data, methods, materials, and software (the version used, as well as the hardware) must all be described and available.

\section{Describing the range of open}

Our workgroup struggled over the question of whether open is a single, absolute state (i.e., something is open only if it meets a specific set of qualities), or whether it could and should be more accurately described as a series of conditions that exist along a spectrum.

We recognized during this deliberation that there are previously articulated definitions of open, including the Budapest definition which defines open access to journal articles as free availability with the functional equivalent of a Creative Commons (CC$\mathrm{BY}$ ) license. ${ }^{2}$ We agreed, however, that in addition to these definitions there is a broad spectrum of open attributes not currently articulated, and further, that open could be reasonably viewed as not an end in itself but as a means for achieving better, more impactful research and for maximizing the value of our research expenditures.

Our conclusion was that openness has a number of dimensions and can be conceptualized as a spectrum, rather than at a single defined point. Our group identified a baseline set of attributes that constitute what the scholarly community currently views as being the minimum requirements for "open" (and without which a research output or process is effectively closed) namely, discoverable, and freely accessible at the point of use. Beyond this baseline, there are attributes that may be more nuanced, and where degrees of openness may occur. Open, therefore, is in many respects a range or scale of less open to more open.

Our group sought to identify points on the openness spectrum without attributing a particular value to these points, in order to avoid designations that would deem some forms of open to be better than others. We 
leave it to individual users applying the spectrum to determine respective value, both because it addresses numerous content types, disciplines and contexts, and because the views of different stakeholders and disciplines vary regarding what constitutes optimum solutions in moral and practical terms.
Our workgroup then identified four dimensions that have a particular bearing on openness: Discoverability, Accessibility, Reusability, and Transparency (DART). These four DART dimensions exist along a spectrum, rather than as binary values (e.g., yes/no, on/off).

\section{The DART Framework}

\begin{tabular}{|c|c|c|}
\hline Dimension & Attributes include & Description \\
\hline Discoverable & $\begin{array}{ll}\text { - } & \text { Indexed by search engines } \\
\text { - } & \text { Sufficient, good quality discovery metadata } \\
\text { - } & \text { Links } \\
\text { - } & \text { Persistent unique identifiers } \\
\text { - } & \text { Opplicit rights statements } \\
& \text { the above attributes) }\end{array}$ & $\begin{array}{l}\text { This may be the most fundamental } \\
\text { baseline condition of open (meaning } \\
\text { that if an object is not discoverable, it } \\
\text { is not open). However, there is a wide } \\
\text { range here, including open with bad } \\
\text { metadata or links and no or faulty } \\
\text { identifiers. }\end{array}$ \\
\hline Accessible & $\begin{array}{ll}\text { - } & \text { Free (in terms of cost) to all users at point } \\
\text { - } & \text { Dof use, in perpetuity } \\
\text { - } & \text { Machine-readable (binary) } \\
\text { - } & \text { Timeliness of availability (spectrum) } \\
\end{array}$ & $\begin{array}{l}\text { Generally drives whether we currently } \\
\text { consider something to be open, alt- } \\
\text { hough many variations exist (taking } \\
\text { into account embargoes and other } \\
\text { conditions). }\end{array}$ \\
\hline Reusable & $\begin{array}{l}\text { - Usable and reusable (including commercial } \\
\text { uses) } \\
\text { - } \quad \text { Able to be further disseminated } \\
\text { - Modifiable }\end{array}$ & $\begin{array}{l}\text { Openness is advanced by having fewer } \\
\text { restrictions on reuse, dissemination } \\
\text { and modification. }\end{array}$ \\
\hline Transparent & $\begin{array}{l}\text { - } \text { Peer review } \\
\text { - } \quad \text { Impact metrics } \\
\text { Transparency in the research process } \\
\text { (based on the Center for Open Science } \\
\text { TOP Guidelines), including data transpar- } \\
\text { ency (metadata and level of availability), } \\
\text { and software (including version and operat- } \\
\text { ing system/hardware) } \\
\text { - } \text { Research design and analytical methods } \\
\text { (plus software and versions), including cita- } \\
\text { tion standards, pre-registration of studies } \\
\text { and of analysis, and replication } \\
\text { Author transparency (funding source, affili- } \\
\text { ations, roles, other disclosures such as } \\
\text { conflict of interest) }\end{array}$ & $\begin{array}{l}\text { Serves the research lifecycle, given that } \\
\text { outputs of research become inputs. } \\
\text { Some of the factors that affect trans- } \\
\text { parency include the software used, } \\
\text { inclusion of data, the transparency of } \\
\text { the peer review process and analytical } \\
\text { methods, and more. }\end{array}$ \\
\hline
\end{tabular}




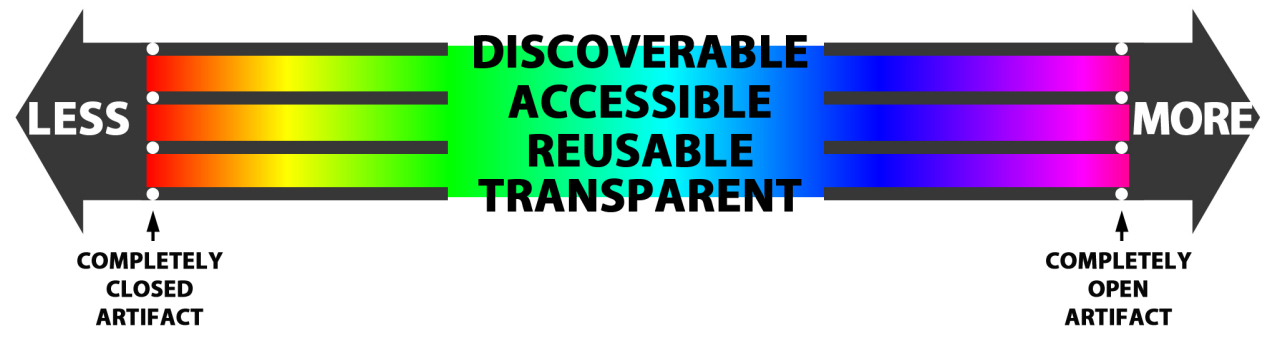

The DART framework was developed over two days of discussions at the OSI meeting in April 2016. We present it now to the community with the aim of expanding the conversations about openness and to help better identify where scholarly artifacts and practices exist along the spectrum of open.

One application of the DART Framework might be to try to identify and assess open spectrums by institution, publication, or discipline, which will allow administrators to design precise, targeted corrections as warranted to improve open access-something that cannot be done with existing methodologies. Another application might be to use this framework to help improve openness across a particular metric (to be determined), such as increasing the number of viewers or users over time.

We welcome comments and input about this framework in order to validate it with the wider community and ensure it reflects thinking and practices from a broad range of stakeholders.

\section{Next steps}

The DART Framework provides identifiable end-points and discrete, quantifiable attributes that we hope will be helpful in terms of describing levels of openness. It enables users to focus efforts in particular areas and allows them to compare practices across institutions, publications and disciplines.

We are sharing this draft conceptual framework with the broader community in order to validate this approach. Once we have received feedback, we intend to further assess the value and relevance of the DART Framework.

Ultimately, we agreed that more openness-that is, moving along the spectrum toward becoming more open on one, some or all of the attributes of openness-is a goal that our entire stakeholder community supports in principle, and that could well have many positive repercussions for research and society. Working together to conceptualize openness as a spectrum with a range of attributes is an important addition to our conversations about openness and our efforts toward this common goal. 


\section{OSI2016 "What is Open?" Workgroup}

Rick Anderson, Associate Dean of Libraries at the University of Utah and PresidentElect, Society for Scholarly Publishing (SSP)

Seth Denbo, Director of Scholarly Communication \& Digital Initiatives, American Historical Association

Diane Graves, Assistant Vice President for Information Resources and University Librarian, Trinity University and Board member, EDUCAUSE

Susan Haigh, Executive Director, Canadian Association of Research Libraries

Steven Hill, Head of Research Policy, Higher Education Funding Council for England (HEFCE)

Martin Kalfatovic, Associate Director, Digital Program and Initiatives, Smithsonian Libraries

Roy Kaufman, Managing Director, New Ventures, Copyright Clearance Center

Catherine Murray-Rust, Dean of Libraries \& Vice Provost for Academic Effectiveness, Georgia Tech

Kathleen Shearer, Executive Director, Confederation of Open Access Repositories

Dick Wilder, Associate General Counsel, Bill \& Melinda Gates Foundation

Alicia Wise, Director of Access and Policy, Elsevier

\section{Notes:}

\footnotetext{
${ }^{1}$ Openness of content within a particular journal often varies, as different articles within a journal may comprise different degrees of openness. The group agreed that the degree of openness of individual articles can be distinct, and that this is a significant factor, given that scholars use articles rather than journals. (We noted that the 'How open is it?' open access spectrum tool, developed by SPARC, PLOS, and the Open Access Scholarly Publishers Association (OASPA), is focused on the components that make journals, not articles, more open. As of June 14, 2016: http://sparcopen.org/wp-content/uploads/2016/01/hoii_guide_rev4_web.pdf.)

${ }^{2}$ See the Budapest Open Access Initiative (2002), as of June 14, 2016: http://www.budapestopenaccessinitiative.org/; the Berlin Declaration on Open Access to Knowledge in the Sciences and Humanities (2003), as of June 14, 2016: http:/ /openaccess.mpg.de/Berlin-Declaration; the Bethesda Statement on Open Access Publishing (2003), as of June 14, 2016: http://legacy.earlham.edu/ peters/fos/bethesda.htm; and The Bouchout Declaration for Open Biodiversity Knowledge Management (2014), as of June 14, 2016: http:/ /www.bouchoutdeclaration.org.
} 